\title{
KONDISI SOSIAL EKONOMI MASYARAKAT PENAMBANG BATU GUNUNG DI DESA MOKALELEO KECAMATAN PURIALA KABUPATEN KONAWE
}

\author{
Muhammad Angga ${ }^{1}$
}

\section{${ }^{1}$ Alumni Pendidikan Geografi FKIP UHO}

\begin{abstract}
Abstrak: Penelitian ini Bertujuan Untuk Mengetahui Bagaimana Kondisi Sosial Ekonomi Masyarakat Penambang Batu Gunung di Desa Mokalelelo Kecamatan Puriala Kabupaten Konawe. Penelitian ini menggunakan metode deskriptif kualitatif. Sampel dalam penelitian ini adalah seluruh masyarakat penambang batu gunung di Desa mokaleleo yang berjumlah 27 orang. Teknik analisisnya menggunakan teknik analisis persentase dan disajikan pada tabel distribusi. Hasil penelitian ini menggambarkan dari sampel yang diambil berjumlah 27 orang responden terdapat 11 orang responden atau 40,74\%, tingkat pendidikan berada pada Sekolah Menengah Atas (SMA). Hal tersebut menggambarkan bahwa, kondisi pendidikan masih dikategorikan rendah. Ditinjau dari kondisi perumahan, sebanyak 25 orang responden atau $92.60 \%$ masih berada dalam kategori rendah yaitu rumah papan, tetapi dapat dikatakan cukup baik karena telah memiliki MCK sendiri, penerangan dari PLN dan sumber air bersih dari PDAM. Ditinjau dari kondisi kesehatan, dilihat dari tempat berobat dikategorikan cukup dimana 14 orang responden atau dengan persentase $51,86 \%$ memilih berobat ke puskesmas dengan alasan bahwa pelayanan yang baik serta pengobatan yang praktis, serta pengobatan medis yang baik. Sedangkan bila ditinjau dari kondisi ekonomi, sebanyak 16 orang responden atau 59.26\% memiliki pendapatan perbulan sebesar $\mathrm{Rp}<2.500 .000$ pendapatan tersebut dikategorikan rendah. Hal ini sesuai dengan penggolongan BPS Tahun 2014, bahwa responden yang berpenghasilan rata-rata Rp. 3.500 .000 - Rp. 4.500 .000 dikategorikan tinggi.
\end{abstract}

Kata Kunci : Kondisi Sosial Ekonomi Masyarakat Penambang Batu Gunung. 


\title{
SOCIAL ECONOMIC CONDITIONS OF MINER IN THE VILLAGE OF MOKALELEO DISTRICT PURIALA KONAWE REGENCY
}

\author{
Muhammad Angga ${ }^{1}$
}

\author{
${ }^{1}$ Alumni of Geography Education FKIP UHO
}

\begin{abstract}
This study aims to determine how the socio-economic conditions of the Stone Mountain Miners in the Village Mokalelelo Puriala District Konawe. This study used descriptive qualitative method. The sample in this research is the entire community of miners of mountain rock in the village mokaleleo, amounting to 27 people. Analysis technique using percentage analysis techniques and presented in the distribution table. The results of this study illustrate from the sample taken amounted to 27 respondents there are 11 people or $40.74 \%$ respondents, the level of education is in high school (SMA). This illustrates that the condition of education is still categorized as low. In terms of housing conditions, as many as 25 respondents or $92.60 \%$ are still in the low category of board house, but it can be quite good because it already has its own toilet, lighting from PLN and water source from PDAM. Judging from the health condition, seen from the place of treatment is categorized enough where 14 respondents or with percentage $51,86 \%$ choose treatment to health center on the grounds that good service and practical treatment, and good medical treatment. Meanwhile, when viewed from economic conditions, as many as 16 respondents or $59.26 \%$ have monthly income of $\mathrm{Rp} 2.500 .000$ income is categorized as low. This is in accordance with the BPS classification of 2014, that respondents who earn an average of Rp. 3.500.000 - Rp. 4.500.000 is categorized as high.
\end{abstract}

Keywords: Socio-Economic Condition of Mountain Miners

\section{PENDAHULUAN}

Pemerintah memandang bahwa pembangunan dibidang ekonomi adalah penting disamping sektor lainya untuk kepentingan bangsa dan negara baik sudut sosial kemasyarakatan, politik, pemerintah, sosial budaya, pertahanan dan keamanan dan sebagainya, karena itu pembangunan dibidang ekonomi perlu mendapatkan perhatian secara lebih sungguhsungguh. Dan untuk memacu pembangunan dibidang ekonomi tersebut, diperlukan peran swasta dalam usaha meningkatkan peran ekonomi kerakyatan. Provinsi sulawesi tenggara yang mayoritas masyarakatnya masih berada di daerah pedesaan dan corak agraris menempatkan sektor pertanian sebagai prioritas utama dalam pembangunannya, utamanya memprioritaskan peningkatan kondisi sosial ekonomi masyarakat, seperti peningkatan pendapatan, kesehatan, dan pendidikan.

Kata sosial menurut Departemen Sosial (Depsos) adalah segala sesuatu yang dipakai acuan dalam berinteraksi antar manusia dalam konteks masyarakat atau komuniti, sebagai acuan berarti sosial bersifat abstrak yang berisi simbol-simbol berkaitan dengan pemahaman terhadap lingkuan, dan berfungsi untuk mengatur tindakan-tindakan yang dimunculkan oleh individu-individu sebagai anggota 
suatu masyarakat. Sehingga demikian, sosial haruslah mencakup lebih dari seorang individu yang terikat pada suatu interaksi, karena lebih dari seorang individu berarti terdapat hak dan kewajiban dari masing-masing individu yang saling berfungsi satu dengan lainnya (http://www.depsos.go.id/)

Usaha pertambangan adalah merupakan kegiatan untuk mengoptimalkan pemanfaatan sumber daya alam tambang (bahan galian) yang terdapat didalam bumi, (Salim,2005:53).

Menurut Salim (2005: 116), bahwa dari pengertian pertambangan rakyat di atas, dapat dikemukaan unsur-unsur pertambangan rakyat meliputi :

1. Unsur pertambangan rakyat

2. Bahan galian yang diusahakan merupakan bahan galian strategis, vital dan galian c.

3. Dilakukan oleh rakyat.

4. Domisili di area tambang rakyat

5. Untuk penghidupan sehari-hari.

6. Diusahakan sederhana.

Usaha menambang batu gunung merupakan proses kerja menggali batu serta memisakan dari induknya yang dilakukan oleh pihak laki-laki dan proses berikutnya adalah memecahkan batu dari ukurannya yang besar. Disamping itu, usaha menggali dan memecahkan batu gunung dilakukan secara bersama antara laki-laki dan perempuan guna mencapai hasil kerja yang sebanyak-banyaknya, sementara peralatan yang digunakan masi sangat sederhana seperti palu, linggis, cangkul dan sekop, bahkan kesehatan fisik menjadi modal utama dalam usaha menambang batu gunung. Namun, dilakukan oleh sistem pemasaran yang lancar dan menguntungkan, serta didukung oleh jalur transportasi dan komunikasi yang cukup baik maka usaha penambangan batu gunung ini dapat menjadi mata pencaharian yang baik untuk para anggota keluarga.Dengan peralatan tradisional yang sangat sederhana masyarakat penambang batu gunung di Desa Mokaleleo menjalankan usahanya untuk memenuhi berbagai jenis kebutuhan sosialnya, ini dilakukan mulai pihak laki-laki yang naik keatas gunung untuk menggali batu dan memecahkan menjadi batu gelondongan, yang kemudian menurunkan kebawah dan setelah terkumpul, perempuan bertugas memecahkan batu gelondongan menjadi batu-batu kecil atau suplit. Namun, kenyataan menunjukan usaha menambang batu gunung yang dilakukan keluarga di Desa Mokaleleo selain untuk memenuhi kebutuhan sosial ekonomi keluarga juga memiliki resiko yang lebih tinggi bila dibandingkan dengan bekerja sebagai petani atau nelayan.

Desa Mokaleleo adalah merupakan salah satu desa pemekaran dari desa induk yaitu Desa Puriala yang wilayahnya dikelilingi dengan Rawa Aopa dan gunung yang merupakan wilayah Taman Nasional Rawa Aopa Watumohai. Desa yang terletak di Kecamatan Puriala Kabupaten Konawe yang memiliki sumber penghasilan penduduk yang menonjol terdapat pada pemanfaatan sumber daya tersebut yakni pada sektor perikanan, pertanian, perdagangan dan sektor sumber daya alam lainnya seperti potensi hasil hutan, potensi peternakan. Dengan potensi tersebut maka diperlukan adanya upaya pengembangan bagi masyarakat yang diharapkan dapat 
meningkatkan keadaan sosial ekonomi keluarga/masyarakat. Dari sisi sosial dapat mendorong perbaikan kualitas hidup berupa tingkat pendidikan, perumahan, dan kesehatan masyarakat, sedangkan dari sisi ekonomi dapat mendorong peningkatan pendapatan masyarakat di Desa Mokaleleo.

Berdasarkan uraian latar belakang tersebut, maka atas alasan inilah sehingga penulis tertarik untuk meneliti dan menulis tentang "Kondisi Sosial Ekonomi Masyarakat Penambang Batu Gunung di Desa Mokaleleo Kecamatan Puriala Kabupaten Konawe".

\section{METODE PENELITIAN}

Penelitian ini dilaksanakan di Desa Mokaleleo Kecamatan Puriala Kabupaten Konawe. Penelitian ini telah dilaksanakan pada bulan Pebruari sampai dengan bulan Maret 2017.

Populasi dalam penelitian ini adalah seluruh masyarakat penambang batu gunung yang berdomisili di Desa Mokaleleo Kecamatan Puriala dengan jumlah sebanyak 27 orang. Sampel dalam penelitian ini adalah diambil semua/seluruh masyarakat/keluarga penamabang batu gunung yang berjumlah 27 orang.

Adapun sumber data dalam penelitian ini adalah:

Data primer yaitu data yang dihimpun dari pengamatan langsung (Observasi) dan wawancara. Data sekunder yaitu data yang diperoleh dari sumber-sumber tertulis maupun data-data yang relevan dengan penelitian.

Jenis data dalam penenlitian ini terbagi 2 yaitu: Data kualitatif yakni data yang dideskripsikan berdasarkan hasil observasi dan wawancara. Data kualitatif yakni data yang diperoleh dan disajikan dalam bentuk tabel dengan menggunakan angka-angka atau persentase.

Dalam usaha untuk mengumpulkan data dalam penelitian ini, maka dilakukan pengumpulan data dengan menggunakan dua metode, yaitu: Studi kepustakaan (library study) yaitu pengumpulan data dan informasi melalui buku-buku, laporanlaporan dan sumber bacaan lainnya yang relevan dengan masalah yang akan diteliti.

Penelitian lapangan (field recearch) yaitu penelitian yang dilakukan secara langsung dilokasi penelitian untuk memperoleh data-data dengan menggunakan teknik sebagai berikut: Pengamatan langsung (observasi) yaitu penelitian yang dilakukan secara langsung dilokasi penelitian guna memperoleh data yang sistematis mengenai aktivitas-aktivitas masyarakat yang bekerja sebagai penambang batu gunung dalam memenuhi kebutuhan sosial ekonomi keluarganya. Wawancara (interview) yaitu pengumpulan data yang diperoleh dengan tatap muka antara peneliti dengan informan, untuk mendapatkan gambaran yang jelas. Dokumentasi, dalam penelitian ini digunakan untuk mendapatkan datadata yang berhubungan dengan penelitian untuk melengkapi data dari wawancara dan observasi/pengamatan mengenai kondisi sosial ekonomi masyarakat penambang batu gunung di Desa Mokaleleo Kecamatan Puriala.

Teknin analisis data yang digunakan dalam penelitian ini adalah teknik analisis secara deskriptif melalui persentase (\%) yakni untuk mendapatkan gambaran secara jelas 
mengenai kondisi sosial ekonomi masyarakat penambang batu gunung di Desa Mokaleleo.

Adapun teknik analisis data antara lain:

- Membuat tabel distribusi frekuensi, yang dimaksud agar data hasil penelitian mudah dipahami

- Dari tabel distribusi frekuensi maka ditentukan persentase setiap butir angket dengan rumus:

$\mathrm{P}=\frac{\mathrm{n}}{\mathrm{N}} \mathrm{X} 100 \%$

(Ali, 1985: 184)

Dimana:

$\mathrm{P}=$ Persentase nilai yang sedang dicari

$\mathrm{n}=$ Frekuensi yang diperoleh setiap option

$\mathrm{N}$ = Jumlah sampel yang digunaka

\section{Indikator Penilaian Kondisi Sosial Ekonomi Masyarakat}

(Badan pusat statistik, 2014) dalam melakukan pengamatan memberikan penilaian dengan kondisi sosial ekonomi masyarakat selalu didasarkan pada indikator-indikator penilain yang bersifat fisik dan non fisik sehinga menggambarkan kondisi yang sesungguhnya. Olehnya itu dalam memberikan penilaian merujuk pada tolak ukur sebagai berikut:
Pendidikan, Prumahan, Kesehatan dan Pendapatan.

\section{HASIL PENELITIAN}

\section{Tingkat Pendidikan Responden}

Menurut UU RI No. 20 Tahun 2003 Pasal 1, pada dasarnya jenjang pendidikan adalah tahapan pendidikan yang ditetapkan berdasarkan tingkat perkembangan peserta didik, tujuan yang akan dicapai, dan kemampuan yang dikembangkan. Tingkat pendidikan adalah jenjang pendidikan formal yang telah diselesaikan oleh responden penambang batu gunung sampai mendapatkan surat keterangan lulus. Tingkat pendidikan turut mempengaruhi cara berpikir dan bertindak seseorang. Pendidikan yang cukup tinggi mengakibatkan sesorang lebih dinamis dalam pengambilan keputusan ketika melakukan kegiatannya, adapun tingkat pendidikan yang dimaksud dalam penelitian ini adalah jenjang pendidikan formal yang telah dilalui oleh para responden. Untuk mengetahui tingkat pendidikan responden akan digambarkan dalam tabel berikut:

Tabel 3.1. Tingkat jenjang pendidikan responden

\begin{tabular}{cccc}
\hline No & $\begin{array}{c}\text { Tingkat } \\
\text { Pendidikan }\end{array}$ & $\begin{array}{c}\text { Jumlah } \\
\text { Responden }\end{array}$ & Persentase \% \\
\hline 1 & SD & 11 & 40.74 \\
\hline 2 & SMP & 5 & 18.52 \\
\hline 3 & SMA & 11 & 40.74 \\
\hline & Jumlah & $\mathbf{2 7}$ & $\mathbf{1 0 0}$ \\
\hline
\end{tabular}

Sumber: Data Primer 2017

Berdasarkan tabel diatas dapat dijelaskan bahwa jenjang pendidikan responden yang terbesar adalah Sekolah Menengah Atas (SMA) sebanyak 11 orang dengan persentase 40,74\%, responden tingkat Sekolah Dasar (SD) sebanyak 11 orang dengan persentase 40,74\%, dan Sekolah 
Menengah Pertama (SMP) sebanyak 5 orang dengan persentase 18,52.
Perumahan Responden

Status Kepemilikan Rumah

Tabel 3.2. Status Kepemilikan Rumah Responden

\begin{tabular}{|c|c|c|c|c|}
\hline \multirow[b]{2}{*}{ No } & \multirow[b]{2}{*}{ Satus Kepemilikan } & \multicolumn{3}{|c|}{ Mata Pencaharian Responden } \\
\hline & & $\begin{array}{c}\text { Penambang } \\
\text { Batu Gunung }\end{array}$ & Jumlah & Persentase \% \\
\hline 1 & Milik Sendiri & 24 & 24 & 88.89 \\
\hline 2 & $\begin{array}{c}\text { Menumpang/Menem } \\
\text { pati }\end{array}$ & 3 & 3 & 11.12 \\
\hline 3 & Sewa & - & & - \\
\hline & Jumlah & 27 & 27 & 100 \\
\hline
\end{tabular}

Sumber: Data Primer 2017

Berdasarkan tabel diatas menunjukan bahwa status kepemilikan rumah responden di Desa Mokaleleo dikategorikan tinggi, sebagian besar adalah milik sendiri yaitu sebesar 24 orang dengan persentase $88,89 \%$, dan sebagian tinggal bersama orang tuanya sebanyak 3 orang dengan persentase $11,12 \%$, sedangkan yang menyewa rumah tidak ada.

\section{Luas Bangunan Rumah}

Tabel 3.3. Luas Bangunani Rumah Responden

\begin{tabular}{ccccc}
\hline \multirow{2}{*}{ No } & Luas Bangunan & \multicolumn{3}{c}{ Mata pencaharian responden } \\
\cline { 3 - 5 } & $40-70 \mathrm{M}^{2}$ & 2 & Jumlah & $\begin{array}{c}\text { Persentase } \\
\%\end{array}$ \\
\hline 1 & $71-101 \mathrm{M}^{2}$ & 21 & 2 & 7.41 \\
\hline 2 & $102-131 \mathrm{M}^{2}$ & 4 & 21 & 77.78 \\
\hline 3 & Junung & 4 & 14.82 \\
\hline & Jumlah & $\mathbf{2 7}$ & $\mathbf{2 7}$ & $\mathbf{1 0 0}$ \\
\hline
\end{tabular}

Sumber: Data Primer Diolah 2017

Berdasarkan tabel diatas, maka responden yang memiliki luas bangunan 71-101 $\mathrm{M}^{2}$ sebanyak 21 responden dengan persentase $77.78 \%$, sedangkan yang memiliki luas bangunan 102-131 $\mathrm{M}^{2}$ sebanyak 4 responden dengan persentase $14.82 \%$, dan yang memiliki luas bangunan 40$70 \mathrm{M}^{2}$ sebanyak 2 responden dengan persentase $7.41 \%$.

\section{Dinding Rumah}

Tabel 3.4. Kondisi Rumah Responden

\begin{tabular}{ccccc}
\hline \multirow{2}{*}{ No } & Dinding Rumah & \multicolumn{3}{c}{ Mata Pencaharian Responden } \\
\cline { 3 - 5 } & Penambang & Jumlah & Persentase \% \\
\hline 1 & Patu Gunung & 25 & 25 & 92.60 \\
\hline 2 & Tembok/Permanen & 2 & 2 & 7.41 \\
\hline 3 & Semi Permanen & - & - & - \\
\hline & Jumlah & $\mathbf{2 7}$ & $\mathbf{2 7}$ & $\mathbf{1 0 0}$ \\
\hline
\end{tabular}

Sumber: Data Primer Diolah 2017 
Berdasarkan informasi dari tabel diatas, menunjukan bahwa keadaan dinding responden sebagian besar menggunakan dinding papan yaitu sebanyak 25 orang/rumah dengan

persentase $92,60 \%$, dan rumah yang menggunakan dinding tembok/permanen yaitu sebanyak 2 orang/rumah dengan persentase $7,41 \%$.

\section{Lantai Rumah Responden}

Tabel.3.5. Kondisi Lantai Rumah Responden

\begin{tabular}{ccccc}
\hline \multirow{2}{*}{ No } & Lantai & \multicolumn{2}{c}{ Mata Pencaharian Responden } & Persentase \\
\cline { 3 - 4 } & Rumah & $\begin{array}{c}\text { Penambang Batu } \\
\text { Gunung }\end{array}$ & Jumlah & \\
\hline 1 & Tanah & 1 & 1 & 3.71 \\
\hline 2 & Semen & 26 & 26 & 96.30 \\
\hline 3 & Tegel & - & - & - \\
\hline & Jumlah & $\mathbf{2 7}$ & $\mathbf{2 7}$ & $\mathbf{1 0 0}$ \\
\hline
\end{tabular}

Sumber: Data diolah 2017

Berdasarkan tabel diatas menunjukan bahwa lantai rumah responden sebagian besar menggunakan lantai semen yaitu sebanyak 26 rumah dengan persentase $96,30 \%$, sedangkan rumah yang berlantaikan tanah sebanyak 1 rumah dengan persentase $3,71 \%$.

\section{Sumber Penerangan Rumah Responden}

Tabel 3.6 Sumber Penerangan Rumah Responden

\begin{tabular}{ccccc}
\hline \multirow{2}{*}{ No } & \multirow{2}{*}{$\begin{array}{c}\text { Sumber } \\
\text { Penerangan }\end{array}$} & $\begin{array}{c}\text { Menambang Batu } \\
\text { Gunung }\end{array}$ & Jumlah & $\%$ \\
\cline { 3 - 5 } & Teplok & - & - & - \\
\hline 1 & Petromaks & - & - & - \\
\hline 2 & Listrik PLN & 27 & 27 & 100 \\
\hline 3 & Jumlah & $\mathbf{2 7}$ & $\mathbf{2 7}$ & $\mathbf{1 0 0}$ \\
\hline
\end{tabular}

Sumber: Data Primer Diolah 2017

Berdasarkan tabel diatas menunjukan bahwa rumah yang ditempati oleh responden yaitu dengan menggunakan penerangan rumah dari PLN, dengan demikian dapat disimpulkan bahwa penerangan yang digunakan oleh responden dapat dokategorikan tinggi karena menggunakan penerangan dari PLN (BPS 2010). 


\section{Status Kepemilikan MCK Responden}

Tabel. 3.7 Status Kepemilikan MCK Responden

\begin{tabular}{ccccc}
\hline \multirow{2}{*}{ No } & Kepemilikan MCK & \multicolumn{3}{c}{ Mata Pencaharian Responden } \\
\cline { 3 - 5 } & $\begin{array}{c}\text { Penambang Batu } \\
\text { Gunung }\end{array}$ & Jumlah & Persentase \% \\
\hline 1 & Sembarang Tempat & - & - & - \\
\hline 2 & Milik Umum & 4 & 4 & 14.82 \\
\hline 3 & Milik Pribadi & 23 & 23 & 85.19 \\
\hline & Jumlah & $\mathbf{2 7}$ & $\mathbf{2 7}$ & $\mathbf{1 0 0}$ \\
\hline
\end{tabular}

Sumber: Data primer diolah 2017

Berdasarkan tabel diatas, bahwa kepemilikan MCK responden milik pribadi yaitu sebanyak 23 responden dengan persentase $85,18 \%$, sedangkan

\section{Kesehatan Responden}

\section{Jenis penyakit yang diderita responden}

Tabel 3.8. Penyakit yang sering diderita responden

\begin{tabular}{ccccc}
\hline \multirow{2}{*}{ No } & Jenis Penyakit & \multicolumn{3}{c}{ Mata Pencaharian Responden } \\
\cline { 3 - 5 } & Demam & $\begin{array}{c}\text { Penambang Batu } \\
\text { Gunung }\end{array}$ & Jmlh & $\%$ \\
\hline 1 & Batuk & 5 & 15 & 55.56 \\
\hline 2 & Sakit Pinggang & 7 & 5 & 18.52 \\
\hline 3 & Jumlah & $\mathbf{2 7}$ & $\mathbf{2 7}$ & $\mathbf{1 0 0}$ \\
\hline
\end{tabular}

Sumber: Data Primer Diolah 2017

Berdasarkan tabel diatas menunjukan bahwa jenis penyakit yang sering diderita oleh responden adalah jenis penyakit demam yaitu sebanyak 15 orang dengan persentase yang menggunakan MCK milik umum yaitu sebanyak 4 responden dengan persentase $14,82 \%$.

\section{Tempat Berobat}

Tabel 3.9. Tempat Pengobatan Responden

\begin{tabular}{ccccc}
\hline \multirow{2}{*}{ No } & \multirow{2}{*}{$\begin{array}{c}\text { Tempat } \\
\text { Berobat }\end{array}$} & $\begin{array}{c}\text { Penambang } \\
\text { Batu Gunung }\end{array}$ & Jumlah & Persentase \% \\
\hline 1 & RSUD & 14 & 14 & 51.86 \\
\hline 2 & Puskesmas & 9 & 9 & 33.34 \\
\hline 3 & Dukun & 4 & 4 & 14.82 \\
\hline & Jumlah & $\mathbf{2 7}$ & $\mathbf{2 7}$ & $\mathbf{1 0 0}$ \\
\hline
\end{tabular}

Sumber: Data Primer Diolah 2017

$55,56 \%$, sakit pinggang yaitu sebanyak 7 orang dengan persentase 25,93\%, penyakit batuk yaitu sebanyak 5 orang dengan persentase

$18,52 \%$

\footnotetext{
Berdasarkan tabel diatas menunjukan bahwa responden yang

berobat di RSUD lebih tinggi yaitu sebanyak 14 orang/responden dengan
} 
persentase $51,86 \%$, sedangkan yang berobat ke Puskesmas sebanyak 9 orang/responden dengan persentase $33,34 \%$, dan yang memilih berobat di

Dukun yaitu sebanyak 4 orang/responden dengan persentase $14,82 \%$.

\section{Kemampuan Pembayaran Pengobatan}

Tabel 3.10. Kemampuan Pembayaran Pengobatan

\begin{tabular}{|c|c|c|c|c|}
\hline \multirow[b]{2}{*}{ No } & \multirow{2}{*}{$\begin{array}{l}\text { Kemampuan } \\
\text { Pembayaran } \\
\text { Pengobatan }\end{array}$} & \multicolumn{3}{|c|}{ Mata Pencaharian Responden } \\
\hline & & $\begin{array}{l}\text { Penambang } \\
\text { Batu Gunung }\end{array}$ & Jmlh & $\%$ \\
\hline 1 & Jamkesmas & 16 & 16 & 59.26 \\
\hline 2 & Biaya Sendiri & 11 & 11 & 40.74 \\
\hline & Jumlah & 27 & 27 & 100 \\
\hline
\end{tabular}

Sumber: Data Primer Diolah 2017

Berdasarkan tabel diatas, responden yang kemampuan pembayaran pengobatannya dengan menggunakan Jamkesmas lebih tinggi yaitu 16 responden dengan persentase $59.26 \%$, sedangkan yang menggunakan biaya sendiri sebanyak 11 responden dengan persentase $40.74 \%$.

\section{Kondisi Ekonomi}

\section{Pendapatan Responden}

Pendapatan adalah penerimaan yang diterima sebagai imbalan atas sesuatu pekerjaan atau jasa tang telah dilakukan setelah dikurangi dengan pengeluaran dalam usaha memperoleh penerimaan tadi. Pandangan bagi masyarakat Desa Mokaleleo adalah penerimaan yang diperoleh dari hasil usaha yang dikerjakan.

Dari hasil penelitian ini diperoleh bahwa pendapatan yang diterima oleh responden bervariasi sesuai pendapatan pekerjaan pokok yang ditekuni oleh mereka untuk memenuhi kebutuhan hidup keluarganya. Untuk lebih jelasnya penulis akan menyajikan tingkat pendapatan responden ditinjau dari pekerjaan utama atau pokok yang ditekuni.

Tabel 3.11. Tingkat Pendapatan Pokok Responden Setiap Bulannya

\begin{tabular}{ccccc}
\hline \multirow{2}{*}{ No } & $\begin{array}{c}\text { Jumlah pendapatan } \\
\text { setiap bulan (Rp) }\end{array}$ & $\begin{array}{c}\text { Menambang batu } \\
\text { gunung }\end{array}$ & Jmlh & $\%$ \\
\hline 1 & Rp. $>4.500 .000$ & 1 & 1 & 3.71 \\
\hline 2 & $\begin{array}{c}\text { Rp. } 3.500 .000- \\
\text { Rp. } 4.500 .000\end{array}$ & 4 & 4 & 14.82 \\
\hline 3 & $\begin{array}{c}\text { Rp. } 2.500 .000- \\
\text { Rp. } 3.500 .000\end{array}$ & 6 & 6 & 22.23 \\
\hline 4 & Rp. $<2.500 .000$ & 16 & 16 & 59.26 \\
\hline & Jumlah & $\mathbf{2 7}$ & $\mathbf{2 7}$ & $\mathbf{1 0 0}$ \\
\hline
\end{tabular}

Sumber: Data Primer Diolah 2017 
Berdasarkan tabel diatas, bahwa pendapatan pokok yang diperoleh responden berdasarkan klasifikasi pendapatan antara Rp. $<2.500 .000$ yakni sebanyak 16 orang dengan persentase $59,26 \%$, pendapatan $\mathrm{Rp}$. 2.500 .000 sampai Rp. 3.500 .000 sebanyak 6 orang dengan persentase $22,23 \%$, pendapatan Rp. 3.500 .000 sampai Rp. 4.500 .000 sebanyak 4 orang dengan persentase $14,82 \%$, sedangkan pendapatan Rp. > 4.500.000 sebanyak 1 orang dengan persentase $3,71 \%$. Jadi kesimpulan dari pendapatan responden penambang batu gunung berada pada pendapatan rendah atau di kategorikan rendah.

\section{Biaya Kebutuhan Responden perbulan}

penambang batu gunung di Desa Mokaleleo juga mengeluarkan biaya untuk memenuhi kebutuhannya seharihari. Adapun biaya masing-masing para responden sangat bervariasi. Hal ini disebabkan karena biaya kebutuhan responden berbeda-beda. Untuk mengetahui biaya kebutuhan responden per bulan dapat dilihat dari tabel beriku:

Tabel 3.12. Biaya Kebutuhan para Responden per bulan

\begin{tabular}{|c|c|c|c|c|}
\hline \multirow[b]{2}{*}{ No } & \multirow[b]{2}{*}{ Biaya Kebutuhan } & \multicolumn{3}{|c|}{ Mata pencaharian responden } \\
\hline & & $\begin{array}{l}\text { Penambang Batu } \\
\text { Gunung }\end{array}$ & Jmlh & $\%$ \\
\hline 1 & $\begin{array}{c}\text { Rp 600.000- } \\
\text { Rp 900.000 } \\
\end{array}$ & 4 & 4 & 14.82 \\
\hline 2 & $\begin{array}{l}\text { Rp 900.000- } \\
\text { Rp 1.200.000 }\end{array}$ & 13 & 13 & 48.15 \\
\hline 3 & $\begin{array}{l}\mathrm{Rp} 1.250 .000- \\
\mathrm{Rp} 1.500 .000\end{array}$ & 9 & 9 & 33.34 \\
\hline 4 & $>\mathrm{Rp} 1.500 .000$ & 1 & 1 & 3.71 \\
\hline & Jumlah & & & $100 \%$ \\
\hline
\end{tabular}

Sumber: Data primer diolah, 2017

Berdasarkan tabel diatas, menunjukkan bahwa kebutuhan para responden per bulan pada kisaran antara $\mathrm{Rp} 900.000$ sampai $\mathrm{Rp}$ 1.200.000 sebanyak 13 orang dengan persentase $\quad 48,15 \% \quad$ sedangkan kebutuhan para responden per bulan pada kisaran antara $\mathrm{Rp} 1.250 .000$ sampai Rp 1.500 .000 sebanyak 9 orang dengan persentase $33,34 \%$ dan kebutuhan para responden per bulan pada kisaran Rp 600.000 sampai Rp 900.000 sebanyak 4 orang dengan persentase $12,82 \%$, serta ada juga kebutuhan para responden per bulan pada kisaran Rp 1.500.000 sebanyak 1 orang dengan persentase $3,71 \%$.
Dalam menghitung jumlah kebutuhan responden, peneliti hanya melihat jumlah uang yang dikeluarkan oleh responden dari berbagai jenis kebutuhan seperti beras, ikan, sayuran, dan belanjaan lainnya. Hal ini disebabkan karena peneliti melihat bahwa jenis kebutuhan diatas merupakan kebutuhan yang sudah pasti dikeluarkan oleh responden. Besarnya biaya kebutuhan responden bervariasi sebab jumlah uang yang mereka keluarkan untuk membeli kebutuhan mereka sangat beragam 


\section{PEMBAHASAN}

Kondisi dari keempat indikator ini yaitu pendidikan bahwa sebagian besar responden telah menamatkan pendidikan formalnya dan ini dapat meningkatkan taraf intelektualitas dan partisipasi masyarakat terhadap pembangunan, sehingga berdasarkan indikator penilaian kondisi pendidikan di Desa Mokaleleo dikategorikan masih rendah.

Kondisi perumahan yakni
sebagian besar responden telah
memiliki perumahan walaupun dalam
bentuk yang sangat sederhana tetapi
dapat dikatakan baik dan layak huni
hal ini ditunjukkan dengan indikator
yang ada didalamnya yakni status
kepemilikan rumah, jenis lantai rumah,
sumber penerangan, sumber air bersih
dan kepemilikan MCK.

Kondisi kesehatan telah menunjukkan hal yang cukup pula dimana kesadaran akan kesehatan cukup dengan menjaga kesehatan dan kebersihan lingkungan. Disaat terserang penyakit sebagian besar responden segera untuk mengobati penyakitnya pada puskesmas setempat atau rumah sakit dengan alasan pelayanan yang baik dan cara pengobatan yang praktis.

Dari segi pendapatan bahwa seluruh responden telah memiliki pendapatan tetap dari pekerjaan pokok. Dan hal ini didasarkan pada indikator penilaian dapat dikategorikan rendah karena pendapatan yang diterima oleh responden sebagian sebesar $\mathrm{Rp}$ $<2.500 .000$ sampai $\operatorname{Rp} 3.500 .000$.

\section{KESIMPULAN}

\section{Tingkat pendidikan}

Tingkat pendidikan adalah jenjang pendidikan formal yang telah diselesaikan oleh responden penambang batu gunung sampai mendapatkan surat keterangan lulus, tingkat pendidikan turut mempengaruhi cara berfikir dan bertindak seseorang. Dengan demikian pendidikan yang ditamatkan responden dikategorikan rendah, karena dari 27 orang responden kondisi pendidikannya rata-rata 11 orang responden terdapat pada SMA dengan SD.

\section{Perumahan}

Perumahan merupakan salah satu kebutuhan pokok bagi setiap kebutuhan manusia, dimana perumahan merupakan salah satu kebutuhan dasar yang harus dipenuhi oleh makhluk hidup yang berfikir karena rumah berfungsi tidak hanya sekedar kebutuhan tempat tinggal atau berlindung saja, tetapi diselaraskan dengan kebutuhan lain seperti keamanan dan kenyamanan dalam lingkungan keluarga maupun dalam masyarakat disekitarnya. Kondisi perumahan responden di Desa Mokaleleo merupakan salah satu indikato untuk menunjukan keadaan sosial ekonomi rumah tangga dalam masyarakat.

\section{Kesehatan}

kesehatan merupakan faktor yang paling penting dalam kehidupan manusia. Tanpa kesehatan, seseorang tidak dapat menjalankan aktivitas sehari-hari demikian pula keluarga/masyarakat penambang batu gunung di Desa Mokaleleo sangat memerlukan kesehatan untuk menjalankan aktivitasnya. 


\section{Kondisi Ekonomi}

Pendapatan adalah penerimaan yang diterima sebagai imbalan atas sesuatu pekerjaan atau jasa yang telah dilakukan setelah dikurangi dengan pengeluaran dalam usaha memperoleh penerimaan tadi. Pendapatan bagi masyarakat Desa Mokaleleo adalah penerimaan yang diperoleh dari hasil usaha yang dikerjakan. Sebanyak 16 responden atau 59,26\%, memiliki pendapatan perbulan sebesar Rp. < 2.500.000. pendapatan tersebut dikategorikan rendah.

\section{DAFTAR PUSTAKA}

BPS, 2014. Indikator Penilaian Sosial Ekonomi Masyarakat. Sulawesi Tenggara

Salim, 2005. Hukum Pertambangan di Indonesia. PT Raja Grafindo Persada .Jakarta

Menurut UU RI No. 20 Tahun 2003.

Tentang Sistem Pendidikan

Nasional

(http://www.depsos.go.id/). 